Eefje Suk

Josine van Mill

Robert Vermeiren

Vladislav Ruchkin

Mary Schwab-Stone

Theo Doreleijers

Dirk Deboutte

\title{
Adolescent suicidal ideation: a comparison of incarcerated and school-based samples
}

Abstract Background The aim of this study was to investigate suicidal ideations and associated psychopathology in two groups of adolescents, a sample of detained youth and a general population sample. In both groups the comparisons of mental health characteristics between suicidal ideators and non-suicidal youth were conducted separately for girls and boys. Methods The study sample consisted of 290 delinquent adolescents [228 boys and 62 girls] from three Flemish juvenile detention centers and 1,548 adolescents [811 boys and 737 girls] from an age-matched schoolbased sample. Both groups were administered the Social and Health Assessment [SAHA], a selfreport survey investigating levels of psychopathology [internalizing and externalizing] and risk-taking behavior. Results Suicidal ideations during the past year were reported by $21.5 \%$ of detained males, compared to $6.7 \%$ in the general population. In females, $58.1 \%$ of detained individuals reported suicidal thoughts during

D. Deboutte

Child and Adolscent Psychiatry

University Antwerp-University Ghent

ZNA University Center Child and

Adolescent Psychiatry Antwerp

Antwerp, Belgium the past year, compared to $14.4 \%$ of the general population. In girls and boys from the general population, both internalizing and externalizing problems were higher in suicidal ideators than in nonsuicidal youth, while in the detention group mainly internalizing problems were higher in suicidal ideators. When comparing detention suicidal ideators with those from the general population, male suicidal ideators scored higher on delinquency, while detained female suicidal ideators also scored higher on posttraumatic stress, but lower on prosocial beliefs. Limitations Information used in this study was solely based on self-report measures only and limited to Flemish adolescents. Conclusion Since suicidal ideation is a frequent problem in detained youth, adequate recognition and treatment seems clinically relevant. While both internalizing and externalizing psychopathology may be an indicator of suicidal ideation in the general population, internalizing problems may be the main clinical predictor in detained youth.

Key words juvenile delinquents - suicidal ideation mental health characteristics 


\section{Introduction}

Suicide represents a major health problem in adolescents, since it is the third leading cause of death in 15-9 year-olds [24]. After decades of research on specific risk factors for suicide, depression remains the best known, although other specific risk factors have also been recognized, such as conduct disorder, and substance abuse [2]. While suicide is a major problem in the general population youth, it has even greater magnitude in specific populations, particularly in detained juvenile delinquents [27]. Until now, mental health characteristics of detained suicidal adolescents have not been extensively investigated. In addition to its direct clinical implications, such research may be of interest, since studies in schoolbased samples have demonstrated that suicidal adolescents represent a heterogeneous group, and that non-aggressive suicidal ideators differ from aggressive suicidal ideators in their mental health profile [29].

Safer [20] reported that $7-10 \%$ of adolescents in the general population [ages $10-19$ ] ever attempted suicide. With respect to gender, the literature has consistently reported greater lifetime prevalence of suicide attempts in female [10.1\%] than in male [3.8\%] adolescents [24]. Although suicidal ideation rates in boys are lower in comparison with girls, completed suicide rates are higher in boys; the boygirl ratio for completed suicide is 2:1 [5]. Delinquent adolescents represent a particularly high-risk group with respect to suicide $[8,19]$. In a review of psychopathology in delinquent adolescents, a $17-30 \%$ prevalence rate of suicide attempts was reported [28]. In addition, completed suicide was reported to be 4.6 times more common in juvenile detention centers than in the general juvenile population [10]. Thus, a better understanding of suicidality in detained youth is needed, in order to identify specific risk factors for these potential life-threatening behaviors, and to develop targeted prevention programs.

Research has demonstrated that risk factors for suicidal behavior may be different for adolescents from different populations. A study [29] in a schoolbased sample of adolescents has shown significant differences in mental health characteristics between suicidal-only and combined suicidal-violent individuals. With regard to clinical risk factors for suicide, the presence of oppositional defiant and conduct disorder was shown to predict suicide attempts in detained males [23]. In reverse, the absence of these two disorders was related to a higher rate of suicide attempts in incarcerated girls [24]. Rohde et al. [18] found that suicidal male delinquents compared to a comparable group of female delinquents reported more depression and social impairment, while suicidal female delinquents reported higher levels of instability and impulsivity. Incarcerated youth are also characterized by high prevalences of other types of mental disorders, with more than two-thirds of females and nearly $60 \%$ of males having one or more psychiatric disorders $[19,26]$. Therefore, the current study aimed at investigating suicidal ideations and associated mental health characteristics in detained youths and in the general population, with the specific focus on those expressing suicidal ideations.

Because suicidal behavior occurs at alarming rates in juvenile detention centers [10], research on risk factors for suicidal behavior is needed. Therefore, the goal of this study was to assess mental health characteristics of detained suicidal adolescents, and to compare them to non-suicidal detained youth and to suicidal and non-suicidal youth from the general population. Because of the widely recognized gender differences with regard to both suicidal behavior and delinquency, the analyses were conducted separately for boys and girls.

\section{Method}

\section{Sample}

The delinquent group consisted of juvenile delinquents from all three juvenile detention centers in the Flanders, Belgium, totaling 314 participants [248 males and 66 females]. Because some participants did not complete all questionnaires, the analyses were conducted on the data obtained from 228 male and 62 female delinquents.

Of the detained males $62.5 \%$ came from Belgium, $20.1 \%$ had a North-African background, $5.3 \%$ had a Turkish background, and 12.1 had another background [such as Asian or Eastern-European]. Of the males in the general population $65.1 \%$ came from Belgium, $1.5 \%$ had a African background, $8.5 \%$ had a Moroccan background, 3.8\% a Turkish background, and the $21,1 \%$ had another background [such as Asian or Eastern-European].

The mean age of the incarcerated males was 16.3 years $[S D=1.12]$ and of the incarcerated females 15.7 years [SD $=1.17]$. As for the control group, an age-matched sample [811 males and 737 females] was selected from a school-based study that utilized the same instruments [mean age of males: 16.3 [SD = 1.08]; females: 15.7 [SD $=1.34$ ]] [28]. 


\section{Procedure}

The delinquent group was recruited from 'youth community centers' for 12-18-years-old adolescents in the Flanders [Belgium], all of whom were referred to these institutions by the juvenile court. All boys and girls who were present in the institutions at the time of the study were surveyed. Prior to the study, adolescents were provided with the detailed description of the study and its aims. It was emphasized that the questionnaire was anonymous, and that refusal to participate would not have consequences with respect to placement or judicial handling. Each participant signed a consent form before starting the study and all adolescents agreed to participate. Because of complicated family structures [divorced parents, illiterate parents, unknown addresses] it was not possible to obtain consent from their parents.

For the school-based sample, nine high schools in Antwerp agreed to participate, selected randomly in order to include the different school systems and levels that exist in Belgium. All students who were present at the day of the survey administration could participate. Students and their parents were notified about the study, and each participant signed a consent form before starting the survey. Students were informed that the questionnaire was anonymous, and that participation was not obligatory. Trained administrators [medical students, psychologists and child psychiatry residents] read the questions out loud, while the students filled in their answers on their copy of the survey.

The study was approved by the relevant Ethics Boards of the school system, the Ministry of Welfare [responsible for the community centers] and by the Institutional Review Board of the University of Antwerp.

\section{Instruments}

The social and health assessment (SAHA), originally developed by Weissberg et al. [30] and later modified $[22,28]$, served as the basis for the survey. The SAHA includes both new scales developed specifically for this project and existing scales. In the past several years, the instrument has been modified substantially by the SAHA Research Evaluation Team [23]. The following scales were used for the present study.

\section{Suicidality}

The question on suicidal ideation was adapted from an existing questionnaire on child and adolescent selfharm [20]. Suicidal ideation was assessed by asking whether the respondent had seriously thought about taking an overdose or harming himself in any other way because he could not bear life anymore. Response options were: 1] No; 2] Yes, during the past month; 3] Yes, during the past year; and 4] Yes, over a year ago. Respondents were subsequently divided in two groups, classifying those who reported suicidal ideations during the past month or the past year as suicidal ideators and all others [those who reported no suicidal ideations, or reported having them over a year ago] as non-suicidal youth.

\section{Depression}

Depressive symptoms were assessed using an adaptation of the Center for Epidemiological StudiesDepression Scale (CES-D; [14]). Both the CES-D [17] and several modified/shortened versions of the scale [3] demonstrated excellent psychometric properties with adolescent populations. In the SAHA study, several original items were either eliminated, or replaced in order to make the scale more age-appropriate [e.g. "I felt that my life had been a failure"; "I could not get going"], and depression-specific [e.g. "I felt fearful"; "My sleep was restless"]. The final version consisted of 15 items, with eleven negative and four positive statements. Respondents reported on the presence of depressive symptoms during the past month on a three-point scale ["Not true"; "Somewhat true"; or "Certainly true"]. The scale had a strong positive correlation of 0.58 with the BASC Depression scale [15], and a good internal consistency in the US [0.83] and Belgian population samples [0.85].

\section{Somatic symptoms}

The scale consisted of 10 items representing somatic symptoms commonly reported by children and adolescents. Symptoms with a prevalence rate above $5 \%$ as assessed in a community sample were used [25]. The respondents reported somatic symptoms during the past month on a three-point scale ["Not true"; "Somewhat true"; or "Certainly true"]. The scale had good internal consistency [Cronbach $\alpha$ of 0.83 for the original American version and 0.81 for the Dutch version].

\section{Anxiety}

This scale consisted of seven items describing somatic experiences [bodily or physiological processes, or sensations] frequently associated with anxiety in children and adolescents. Items related to somatic anxiety are commonly used in anxiety scales $[1,9,16]$. 
Items in the present scale were compiled by the authors after a series of discussions with pediatricians and mental health professionals. Symptoms were listed after an introductory phrase ["Often when I worry..."] with response options of "Not True, Somewhat True, or Certainly True for you". In order to exclude possible overlap between the constructs, a joint factor analysis with oblique rotation was conducted for somatic anxiety and somatic complaints scales. The factor structure included two separate factors for somatic anxiety and somatic complaints, explaining $43 \%$ of the variance. The Cronbach $\alpha$ for the somatic anxiety scale was 0.78 .

\section{PTS}

Post-traumatic stress was assessed with the Dutch version of the child posttraumatic stress-reaction index (CPTS-RI) [13], a 20 item self-report questionnaire. Response options for each item were: 'None', 'A little', 'Some', 'Often', or 'Most of the time'. After summing all 20 items, a total score between 12 and 24 was described to indicate mild PTS, of 25-39 moderate PTS, of 40-59 severe PTS, and of 60 very severe PTS. In traumatized children, strong correlations have been demonstrated between these CPTSD-RI categories and a clinical interview-based diagnosis [13]. Cronbach alpha for this scale was 0.85 .

\section{Sensation seeking}

Sensation seeking behavior was assessed by eight questions, inquiring about such behaviors as going to unfamiliar places, doing bungee jumping and going to wild parties. Answers were given on a five-point scale, ranging from 'Strongly disagree' to 'Strongly agree' [for example 'I like going to wild parties']. The Cronbach $\alpha$ for this scale was 0.83 .

\section{Prosocial beliefs}

This construct was measured by a ten-item scale, with seven items derived from the Disapproval of Deviancy Scale from the School Health Study [5] and three items ["hurting someone badly"; "being a look-out for a drug dealer"; and "carrying a gun"] added by the SAHA Research Team [21]. Respondents were asked to rate on a four-point Likert-type scale [ranging from "Not wrong" to "Very wrong"] how wrong it is to be involved in various antisocial activities [stealing, lying, damaging property, hurting someone badly in a fight, starting a fist-fight etc.], with a total score ranging from 10 to 40 . Higher scores corresponded to stronger disapproval of antisocial behavior, reflecting higher levels of prosocial beliefs. Coefficients alpha for this scale was 0.89 .

\section{Delinquency}

The Antisocial Behavior Scale [13, 22] included three subscales assessing antisocial behaviors of different severity, identified based on a factor analysis with the US school-based data. The respondents were asked to report on a 5-point scale how many times [ranging from " 0 times" to " 5 or more times"] they were involved in a number of antisocial behaviors during the past year. Subscales were: 1] Conduct Problems; four items describing relatively mild behavior problems, such as lying to a teacher or a parent, staying out all night without permission, and skipping school [internal consistency of 0.78 for Dutch version]. 2] Less Severe Delinquency; six items describing nonviolent antisocial behavior, such as shoplifting, stealing a motorcycle or a car, pick pocketing, and being high at school after drinking alcohol or from smoking marijuana [Cronbach alpha of 0.80 for Dutch version]. 3] Severe Antisocial Behavior; eight items, pertaining to relatively serious aggressive antisocial behaviors, including starting a fistfight, participating in a gang fight, hurting someone badly in a fight, being arrested by police, being drunk at school, and carrying a blade or knife at school [Cronbach alpha of 0.82 for Dutch version].

\section{Statistical analyses}

For the statistical analyses, SPSS 10.0 was used. First, the prevalences of suicidal ideation are reported for the detention group and the general population, separately for boys and for girls. Prevalence rates of suicidal ideations in the different samples are compared by means of chi-square tests. Second, mean level differences of the mental health problems are compared between suicidal ideators and non-suicide youth from both populations, and between populations, using analysis of variance tests (ANOVA). Post-hoc tests [using Bonferroni corrections for multiple comparisons] were also conducted, comparing suicidal ideators and non-suicidal youth within each population, and suicidal ideators from the detention group with suicidal ideators from the general population.

\section{Results}

\section{Suicidality}

Suicidal ideation during the past month/year was reported by $21.5 \%$ [49 of 228] of detained males, com- 
pared to $6.7 \%$ [54 of 811 ] in the general population $\left[\chi^{2}=43,8 d f 1,038 ; P<0.001\right]$. In females, $58.1 \%$ [36 of 62] of incarcerated individuals reported suicidal thoughts during the past month/year, compared to $14.4 \%$ [111 of 773$]$ in the general population $\left[\chi^{2}=75.6 \mathrm{df} 834 ; P<0.001\right]$.

\section{Relationship between suicidality and mental health characteristics}

\section{Males}

In the detention group (Table 1), suicidal males scored significantly $[P<0.05]$ higher than non-suicidal males on depression, somatization, anxiety, PTS and less severe delinquency; while this was not so for sensation seeking, prosocial beliefs, and severe delinquency. In the general population, suicidal males were significantly higher than non-suicidal males on all variables of interest, except for sensation seeking. When comparing suicidal ideators in the general population with detained suicidal ideators, only less severe and severe delinquency were higher in the detention suicide group.

\section{Females}

In the detention group (Table 2), suicidal female ideators scored higher than non-suicidal females on depression, anxiety and PTS; while this was not so for other variables of interest. In the general population, suicidal females scored higher than non-suicidal female ideators on all variables of interest. When comparing suicide ideators from the detention and normal population groups, levels of PTS, prosocial beliefs and both types of delinquency were higher in the detention group.

\section{Discussion}

The aim of this study was to investigate suicidal ideations in detained and school-based samples of adolescents, and to explore mental health characteristics of suicide ideators in detention, by comparing them to non-suicidal detainees, and to suicide ideators from the general population. Compared to the normal population, both male and female detained adolescents had about three times higher rates of suicide

Table 1 Results males: comparison of mental health characteristics in male adolescents with and without suicidal ideations from the general population and detention centers

\begin{tabular}{|c|c|c|c|c|c|c|c|c|}
\hline & \multicolumn{3}{|c|}{ General population } & \multicolumn{3}{|l|}{ Detention center } & \multirow[t]{2}{*}{$F[d f]$} & \multirow[t]{2}{*}{ [2]-[4] } \\
\hline & Non-suicidal [1] & Suicidal [2] & {$[1]-[2]$} & Non-suicidal [3] & Suicidal [4] & [3]-[4] & & \\
\hline Depression (mean \pm SD) & $3.6[3.4]$ & $8.8[4.3]$ & $* * *$ & $5.9[4.2]$ & $8.1[4.8]$ & $* * *$ & $62.1[3.1019]$ & \\
\hline Somatization (mean \pm SD) & $3.8[3.8]$ & $7.8[4.3]$ & $* * *$ & $4.5[3.9]$ & $6.5[4.7]$ & ** & 25.1 [3.1032] & \\
\hline Anxiety $($ mean $\pm S D)$ & $8.2[4.9]$ & $11.0[5.4]$ & $* * *$ & $7.4[5.1]$ & $9.6[6.6]$ & ** & 8.3 [3.1032] & \\
\hline PTS (mean \pm SD) & $17.1[10.5]$ & 31.2 [13.3] & $* * *$ & $23.4[12.2]$ & $31.5[14.5]$ & $* * *$ & $58.1[3.1030]$ & \\
\hline Sensation seeking (mean $\pm S D$ ) & $28.3[7.2]$ & $29.5[7.3]$ & & $28.7[7.8]$ & $28.2[9.4]$ & & $0.6[3.917]$ & \\
\hline Prosocial beliefs (mean \pm SD) & $31.1[7.7]$ & $28.0[7.9]$ & $* *$ & $26.1[9.4]$ & $25.1[8.8]$ & & $25.3[3.1028]$ & \\
\hline \multicolumn{9}{|l|}{ Delinquency } \\
\hline Less $($ mean $\pm S D)$ & $1.6[3.2]$ & $3.8[4.7]$ & $* * *$ & $8.6[6.1]$ & $10.0[6.2]$ & * & $181.1[3.1027]$ & $* * *$ \\
\hline Severe $($ mean $\pm S D)$ & $2.4[4.2]$ & $5.0[5.7]$ & $* * *$ & $11.0[6.9]$ & $12.5[7.2]$ & & $180.9[3.1030]$ & $* * *$ \\
\hline
\end{tabular}

${ }^{*}<0.05 ;{ }^{* *}<0.01 ;{ }^{* * *}<0.001$

Table 2 Results females: comparison of mental health characteristics in female adolescents with and without suicidal ideations from the general population and detention centers

\begin{tabular}{|c|c|c|c|c|c|c|c|c|}
\hline & \multicolumn{3}{|c|}{ General population } & \multicolumn{3}{|l|}{ Detention center } & \multirow[t]{2}{*}{$F[d f]$} & \multirow[t]{2}{*}{ [2]-[4] } \\
\hline & Non-suicidal [1] & Suicidal [2] & {$[1]-[2]$} & Non-suicidal [3] & Suicidal [4] & [3]-[4] & & \\
\hline Depression (mean \pm SD) & $5.3[4.1]$ & $11.4[4.9]$ & $* * *$ & $10.0[5.6]$ & $12.5[4.6]$ & * & $92.0[3.821]$ & \\
\hline Somatization (mean $\pm S D$ ) & $5.6[4.2]$ & $9.9[4.7]$ & $* * *$ & $7.7[5.7]$ & $8.6[4.9]$ & & $35.2[3.826]$ & \\
\hline Anxiety (mean $\pm S D$ ) & $10.0[5.4]$ & $13.9[6.2]$ & $* * *$ & $10.2[5.4]$ & $13.6[6.4]$ & * & 19.2 [3.827] & \\
\hline PTS (mean \pm SD) & $20.3[12.5]$ & $36.5[15.9]$ & $* * *$ & $33.6[16.0]$ & $43.0[14.9]$ & ** & $78.7[3.822]$ & * \\
\hline Sensation seeking (mean \pm SD) & $25.2[7.1]$ & $28.7[7.3]$ & $* * *$ & $27.3[8.6]$ & $29.6[7.2]$ & & $10.7[3.824]$ & \\
\hline Prosocial beliefs (mean \pm SD) & $36.0[6.2]$ & $32.3[7.9]$ & $* * *$ & $29.2[7.5]$ & $26.7[9.2]$ & & $34.7[3.823]$ & $* * *$ \\
\hline \multicolumn{9}{|l|}{ Delinquency } \\
\hline Less $($ mean $\pm \mathrm{SD})$ & $0.4[1.3]$ & $1.8[3.7]$ & $* * *$ & $4.8[5.3]$ & $5.4[5.2]$ & & $88.2[3.831]$ & $* * *$ \\
\hline Severe $($ mean $\pm S D)$ & $0.4[1.2]$ & $1.3[3.6]$ & $* * *$ & $8.3[5.7]$ & $9.3[6.0]$ & & $269.8[3.831]$ & $* * *$ \\
\hline
\end{tabular}

${ }^{*}<0.05 ;{ }^{* *}<0.01 ;{ }^{* * *}<0.001$ 
ideation, with over half of the female detention group reporting suicide ideation. With respect to risk factors, detained suicide ideators reported higher levels of almost all internalizing problems, as compared to detained non-suicidal youth, while in the normal population, suicide ideators reported higher levels of both internalizing and externalizing problems. As expected, detained suicide ideators scored higher on delinquency than suicide ideators from the general population. Surprisingly, suicide ideators from the detention center did not differ from suicide ideators from the general population except for delinquency. Findings from this study bear substantial clinical implications, since the alarmingly high levels of suicidal ideation emphasize the necessity of adequate mental health screening of detained youth, while specific risk factors for suicide ideation tend to differ between detained and general population youth.

Existing studies on the prevalence of suicidal phenomena in detained youth have consistently reported high rates of both suicidal ideations and intent, although the overall prevalences of suicidality described in such studies differ. For example, while Penn et al. [11] found that $32 \%$ of incarcerated youths reported suicidal ideation/behavior, Rohde et al. [18] showed that $14 \%$ of juvenile delinquents report current and 34\% lifetime suicidal ideations. Methodological reasons may explain this diversity, and include differences in time frames for the reported behaviors and inconsistent definition of the suicidal behaviors investigated. For those reasons, current findings may be difficult to compare to earlier studies. With respect to gender, Morris [10] found that incarcerated females reported more suicidal ideation in the past year [40\%] compared with incarcerated males [19\%]. No study has however compared delinquent youth with a general population sample using the same instrument. In this study, the 1 year prevalence of suicidal ideation was about $20 \%$ for delinquent males and over $50 \%$ for delinquent females, rates that are substantially higher than those observed in the general population. The gender specific differences found were not surprising, since the previous studies have similarly reported higher rates of suicidal ideation in females compared to males [24]. The higher rates of suicidal ideations in incarcerated adolescent females may as well reflect the higher prevalence rates of mental disorders in female compared to male detainees. However, because boys are more often involved in completed suicides than girls [24], the lower prevalence of suicidal ideation in delinquent males in this study should not be overlooked.

The psychopathological 'profile' of male suicide ideators from the general population did not differ substantially from those in the detention centers, except for externalizing problems, as expected. How- ever, even though the differences are small, one can not conclude from this study that internalizing and externalizing problems reported in both groups contribute similarly to suicidal ideation. In the detention group, being detained may itself have an impact on suicidal ideation, in addition to the contribution of psychopathological conditions. Therefore, internalizing problems may exert a stronger influence in the general population. On the other hand, female adolescents in the general population and in detention centers do not share the same psychopathological profile. For example, suicidal detained females have significantly high levels of PTS [6]. This aspect may be of particular importance with respect to intervention in detained females. It is additionally likely that incarceration itself functions as a retraumatization experience, an aspect to be taken into account in this population [12]. As the current study is cross-sectional, further study is needed in order to elucidate time-related changes and hence, usefulness of these aspect in intervention.

\section{Limitations}

First, information used in this study was solely based on the self-report measures. Although it has been recognized that self-report measures can be considered a reliable source of information with regard to externalizing behaviors [7], possible bias associated with self-report could not be avoided. Therefore, future research should include interview method containing information from other sources [4]. Because of limited funding for this study, conducting psychiatric interviews was not possible. Furthermore, it is unknown how reliable questionnaires in detention centers are, for example because of problems of language. Second, the study was limited to Flemish adolescents only. Because of the regional differences in the legal procedures, detained youth may differ substantially between different countries, which suggests that replication of our findings in others samples is warranted.

\section{Clinical implications}

The clinical implications of this study are straightforward. Since detained adolescents exhibit high levels of suicidal ideations, detained youth should be subject to a comprehensive psychological and psychiatric diagnostic assessment. Considering the risks associated with this potentially life-threatening condition, the screening for suicide should be conducted shortly after incarceration and repeated at regular intervals during detention. If a high risk of suicidality is suspected, the screening procedure must be followed by 
thorough diagnostic child psychiatric assessment and treatment of underlying psychiatric disorders.

The differences in comorbid mental health problems between the detained and non-detained suicidal ideators may bear particular relevance with regard to treatment issues. In detained youth, specific clinical attention is needed to treating internalizing and externalizing problems that is considered represent a particular risk factor. In addition, it should be investigated which environmental factors contribute to suicidal ideation and to what extent factors related to being locked up pose individuals at risk. Recognizing such factor may bear relevance with regard to handling youngsters and minimizing the risk of adverse effects.

\section{References}

1. Birmaher B, Khetarpal S, Brent D, Cully M, Balach L, Kaufman J, Neer SM (1997) The screen for child anxiety related emotional disorders (SCARED): scale construction and psychometric characteristics. J Am Acad Child Adolesc Psychiatry 36:545-553

2. Brent DA, Perper JA, Moritz G, Allman C, Friend A, Roth C, Schweers J, Balach L, Baugher M (1993) Psychiatric risk factors for adolescent suicide: a casecontrol study. J Am Acad Child Adolesc Psychiatry 32:521-529

3. Carpenter JS, Andrykowski MA, Wilson J, Hall LA, Rayens MK, Sachs B, Cunningham LL (1998) Psychometrics for two short forms of the Center for Epidemiologic Studies-Depression Scale. Issues Ment Health Nurs 19:481-494

4. Colins O, Vermeiren R, Schuyten G, Broekaert E, Soyez V (2008) Informant agreement in the assessment of disruptive behavior disorders in detained minors in Belgium: a diagnosis-level and symptom-level examination. J Clin Psychiatry 69:141-148

5. Dervic K, Brent DA, Oquendo MA (2008) Completed suicide in childhood. Psychiatr Clin North Am 31:271-291

6. Hamerlynck SM, Doreleijers TA, Vermeiren R, Jansen LM, Cohen-Kettenis PT (2008) Aggression and psychopathology in detained adolescent females. Psychiatry Res 159:77-85

7. Junger-Tas J (1994) Delinquent behavior among young people in the western world. Kugler Publications, Amsterdam

8. Kempton T, Forehand R (1992) Suicide attempts among juvenile delinquents; the contribution of mental health factors. Behav Res Ther 30:537-541

9. March JS, Parker JD, Sullivan K, Stallings P, Conners CK (1997) The multidimensional anxiety scale for children (MASC): factor structure, reliability, and validity. J Am Acad Child Adolesc Psychiatry 36:554-565
10. Morris RE, Harrison EA, Knox GW, Tromanhauser E, Marquis DK, Watts LL (1995) Health risk behavioral survey from 39 juvenile correctional facilities in the United States. J Adolesc Health 17:334-344

11. Penn JV, Esposito CL, Schaeffer LE, Fritz GK, Spirito A (2003) Suicide attempts and self-mutilative behavior in a juvenile correctional facility. J Am Acad Child Adolesc Psychiatry 42:762-769

12. Plattner B, The SS, Kraemer HC, Williams RP, Bauer SM, Kindler J, Feucht M, Friedrich MH, Steiner H (2007) Suicidality, psychopathology, and gender in incarcerated adolescents in Austria. J Clin Psychiatry 68:1593-1600

13. Pynoos RS, Goenjian A, Tashjian M, Karakashian M, Manjikian R, Manoukian G, Steinberg AM, Fairbanks LA (1993) Posttraumatic stress reactions in children after the 1988 Armenian earthquake. Br J Psychiatry 163:239-247

14. Radloff LS (1977) The CES-D scale: a self-report depression scale for research in the general population. J Appl Psychol Meas 1:385-401

15. Reynolds CRKR (1992) Behavior assessment system for children [BASC]. American Guidance Service, Circle Pines

16. Reynolds CR, Richmond BO (1978) What I think and feel: a revised measure of children's manifest anxiety. J Abnorm Child Psychol 6:271-280

17. Roberts RE, Lewinsohn PM, Seeley JR (1991) Screening for adolescent depression: a comparison of depression scales. J Am Acad Child Adolesc Psychiatry 30:58-66

18. Rohde P, Seeley JR, Mace DE (1997) Correlates of suicidal behavior in a juvenile detention population. Suicide Life Threat Behav 27:164-175

19. Ruchkin VV, Schwab-Stone M, Koposov RA, Vermeiren R, King RA (2003) Suicidal ideations and attempts in juvenile delinquents. J Child Psychol Psychiatry 44:1058-1066

20. Safer DJ (1997) Self-reported suicide attempts by adolescents. Ann Clin Psychiatry 9:263-269
21. Schwab-Stone ME, Ayers TS, Kasprow W, Voyce C, Barone C, Shriver T, Weissberg RP (1995) No safe haven: a study of violence exposure in an urban community. J Am Acad Child Adolesc Psych 34:1343-1352

22. Schwab-Stone M, Chen C, Greenberger E, Silver D, Lichtman J, Voyce C (1999) No safe haven. II: the effects of violence exposure on urban youth. J Am Acad Child Adolesc Psychiatry 38:359-367

23. Shaffer D, Gould MS, Fisher P, Trautman P, Moreau D, Kleinman M, Flory M (1996) Psychiatric diagnosis in child and adolescent suicide. Arch Gen Psychiatry 53:339-348

24. Spirito A, Overholser J (2003) Evaluating and treating adolescent suicide attempters: from research to practice. Academic Press, San Diego

25. Taylor DC, Szatmari P, Boyle MH, Offord DR (1996) Somatization and the vocabulary of everyday bodily experiences and concerns: a community study of adolescents. J Am Acad Child Adolesc Psychiatry 35:491-499

26. Teplin LA, Abram KM, McClelland GM, Dulcan MK, Mericle AA (2002) Psychiatric disorders in youth in juvenile detention. Arch Gen Psychiatry 59:1133-1143

27. Vermeiren R (2003) Psychopathology and delinquency in adolescents: a descriptive and developmental perspective. Clin Psychol Rev 23:277-318

28. Vermeiren R, Schwab-Stone M, Deboutte D, Leckman PE, Ruchkin V (2003) Violence exposure and substance use in adolescents: findings from three countries. Pediatrics 111:535-540

29. Vermeiren R, Schwab-Stone M, Ruchkin VV, King RA, Van HC, Deboutte D (2003) Suicidal behavior and violence in male adolescents: a school-based study. J Am Acad Child Adolesc Psychiatry 42:41-48

30. Weissberg RP, Voyce CK, Kasprow WJ, Arthur MW, Shriver TP (1991) The social and health assessment. Yale Child Study Center, Chicago, IL 